\title{
Una Promesa no cumplida: Respuesta Institucional al Goce Efectivo de Derechos a la Población en Situación de Desplazamiento Forzado en el Suroccidente Colombiano - Estudio de caso en los municipios de Buenaventura y Pasto.
}

\section{Resumen:}

Este artículo muestra algunos de los resultados del proceso de análisis sobre la acción y gestión que las distintas entidades responsables del sistema de atención a las personas víctimas del desplazamiento, llevan a cabo. Señalando particularidades para los casos del Municipio de Buenaventura (Valle del Cauca) y el Municipio de Pasto (Nariño). Es una apuesta por mostrar las falencias del sistema y en algunos casos la urgencia de su transformación.

\begin{abstract}
Abtrac:
This article shows some of the results of the analysis and management action that the various entities responsible for the system of care for victims of displacement performed. Noting the particular case of the municipality of Buenaventura (Valle del cauca) and the municipality of Pasto (Nariño). It is a bid to show the shortcomings of the system and in some cases the urgency of its transformation.
\end{abstract}

\section{Key Words:}

System of care for people Experiencing displacemen

Obstacles and Shortcomings

Unconstitutional state of affairs

\section{Palabras Claves:}

Sistema de Atención a las Personas en Situación de Desplazamiento

Obstáculos y Deficiencias

Estado de cosas inconstitucionales

\section{A Manera de Introducción}

Este artículo es producto del proceso de investigación llevado a cabo por algunos de los y las profesionales del grupo Sujetos Sociales y Acción Colectiva: Claudia Galeano Martínez (Coordinadora de la Investigación); Claudia Belarmina Ortiz Salinas; Alba Lucía Aguirre Feijoo; Alexander Castaño Pérez; David Fernando Erazo Ayerbe; Sheila Andrea Gómez

Peñaloza; Federico Guillermo Muñoz; Katherine Tabares Acevedo; Irina Ivette Torres Pabón; Carlos Alberto Valderrama Rentería (Investigadores/Investigadoras).

El objetivo General que guió el proceso de investigación fue: 
"Analizar la respuesta de las organizaciones gubernamentales frente al goce efectivo de los derechos de la población desplazada en los Municipios de Buenaventura y Pasto".

A su vez, las claves teóricas se enmarcan en los lineamientos que la Comisión de Seguimiento señaló como tales:

- Informe de la Comisión Nacional de Seguimiento a la Política Pública de desplazamiento forzado, 2007.

- Guía de atención integral a la población desplazada por la violencia en Colombia.

- Autos 109 de 2007 y 116 de 2008 - Corte Constitucional

- Marco general de derechos de la población desplazada por la violencia en Colombia.

- Política pública de prevención y atención a la población desplazada por la violencia en Colombia.

- Información general y responsabilidades de las entidades del Sistema Nacional de Atención Integral a la Población Desplazada por la Violencia, SNAIPD.

- Sentencia T-025 - Corte Constitucional

- Conferencia del Profesor Marco Romero sobre Goce Efectivo de Derechos de la Población Desplazada. Retroalimentación de la lectura del informe de la Comisión, 2007.

- Programas, proyectos y acciones desarrollados por las entidades del SNAIPD.

- Revisión del Auto 109 de 2007 y 116 de 2008

En la siguiente matriz metodológica, puede observarse la estructura, categorías previas indagadas y las fuentes de los datos:

\begin{tabular}{|c|c|c|c|c|}
\hline $\begin{array}{c}\text { OBJETIV } \\
\text { O } \\
\text { ESPECÍFI } \\
\text { CO }\end{array}$ & $\begin{array}{c}\text { CATEGORÍ } \\
\text { A/VARIAB } \\
\text { LE }\end{array}$ & SUBCATEGORÍAS & $\begin{array}{c}\text { FUENTE DE } \\
\text { INFORMACI } \\
\text { ÓN }\end{array}$ & TÉCNICA \\
\hline $\begin{array}{l}\text { Identificar } \\
\text { los } \\
\text { desarrollos } \\
\text { institucional } \\
\text { es y de la } \\
\text { política }\end{array}$ & $\begin{array}{l}\text { Desarrollos } \\
\text { institucionale } \\
\text { s para el goce } \\
\text { efectivo de } \\
\text { los derechos } \\
\text { de las P.S.D., }\end{array}$ & \begin{tabular}{ll}
\multicolumn{1}{c}{ Propuestas, } & \multicolumn{2}{c}{ visiones } \\
institucionales & sobre la \\
problemática. \\
- Noción de GED que tienen las \\
instituciones. \\
- Conocimiento & de
\end{tabular} & $\begin{array}{l}\text { Funcionarios } \\
\text { (Directivos) en } \\
\text { Pasto y } \\
\text { Buenaventura } \\
\text { de: } \\
\text { Acción Social, }\end{array}$ & $\begin{array}{l}\text { Revisión } \\
\text { documental: } \\
\text {-Plan de Desarrollo } \\
\text { Municipal y } \\
\text { Departamental } \\
\text { actual y anterior. }\end{array}$ \\
\hline
\end{tabular}




\begin{tabular}{|c|c|c|c|c|}
\hline $\begin{array}{l}\text { pública para } \\
\text { el goce } \\
\text { efectivo de } \\
\text { los derechos } \\
\text { de las } \\
\text { P.S.D., en } \\
\text { lo local. }\end{array}$ & $\begin{array}{l}\text { en lo local. } \\
\text { Desarrollos } \\
\text { de la política } \\
\text { pública para } \\
\text { el goce } \\
\text { efectivo de } \\
\text { los derechos } \\
\text { de las P.S.D., } \\
\text { en lo local. }\end{array}$ & $\begin{array}{l}\text { jurisprudencia sobre los } \\
\text { indicadores. } \\
\text { - Descentralización de la política } \\
\text { (formas de operacionalización de } \\
\text { la política-Decretos u ordenanzas } \\
\text { emitidas para la atención a la } \\
\text { P.S.D, Promoción y seguimiento } \\
\text { a la conformación y el } \\
\text { funcionamiento de los Comités } \\
\text { Territoriales de Atención Integral } \\
\text { a la Población Desplazada). } \\
\text { - Coherencia entre los objetivos de } \\
\text { la política pública, los recursos } \\
\text { existentes y las estrategias } \\
\text { utilizadas por las instituciones en } \\
\text { la atención de PSD. } \\
\text { - Participación de las P.S.D en las } \\
\text { propuestas relacionadas con } \\
\text { política pública del GED }\end{array}$ & $\begin{array}{l}\text { Defensoría } \\
\text { Regional del } \\
\text { Pueblo, } \\
\text { Secretaría de } \\
\text { Gobierno } \\
\text { Municipal y } \\
\text { Departamental, } \\
\text { ICBF, } \\
\text { Secretaría de } \\
\text { Salud, } \\
\text { Secretaria de } \\
\text { Educación, } \\
\text { Secretaria de } \\
\text { Agricultura y } \\
\text { Medio } \\
\text { Ambiente. } \\
\text { Comités } \\
\text { municipales y } \\
\text { Departamental } \\
\text { es (Secretaría } \\
\text { Técnica de } \\
\text { Pasto } \\
\text { Buenaventura). }\end{array}$ & $\begin{array}{l}\text {-PIU, } \\
\text { - Ley 387, Decreto } \\
250 \text { de 2005, } \\
\text { Autos, Ordenanzas } \\
\text { y Decretos } \\
\text { Departamental y } \\
\text { Municipal. } \\
\text {-Planes } \\
\text { plurianuales } \\
\text { /presupuestos. } \\
\text {-Entrevistas } \\
\text { semiestructurada. }\end{array}$ \\
\hline $\begin{array}{l}\text { Describir } \\
\text { las } \\
\text { estrategias, } \\
\text { metodología } \\
\text { s y rutas } \\
\text { críticas } \\
\text { existentes } \\
\text { para } \\
\text { viabilizar el } \\
\text { cumplimien } \\
\text { to de los } \\
\text { indicadores } \\
\text { de goce } \\
\text { efectivo de } \\
\text { los derechos } \\
\text { de las } \\
\text { P.S.D., } \\
\text { desde las } \\
\text { organizacio } \\
\text { nes gubernamen } \\
\text { tales }\end{array}$ & $\begin{array}{l}\text {-Estrategias y } \\
\text { Metodologías } \\
\text { para } \\
\text { viabilizar el } \\
\text { cumplimiento } \\
\text { del GED } \\
\text {-Rutas } \\
\text { críticas para } \\
\text { viabilizar el } \\
\text { cumplimiento } \\
\text { del GED }\end{array}$ & $\begin{array}{l}\text { - Programas, proyectos y acciones } \\
\text { para viabilizar el goce efectivo de } \\
\text { Derechos. } \\
\text { - Aplicabilidad del enfoque } \\
\text { diferencial por grupo etareo, } \\
\text { étnico, género y discapacidad en } \\
\text { las estrategias implementadas por } \\
\text { las instituciones para el GED de la } \\
\text { PSD. } \\
\text { - Formas que las instituciones } \\
\text { aplican para evaluar las estrategias } \\
\text { utilizadas para el GED: } \\
\text { procedimientos, informes de } \\
\text { gestión, rendición de cuentas. } \\
\text { - Mecanismos que desarrollan } \\
\text { las instituciones para que las PSD } \\
\text { conozcan la oferta institucional. } \\
\text { - Procedimientos } \\
\text { requerimientos necesarios para } \\
\text { acceder a la oferta institucional. }\end{array}$ & $\begin{array}{l}\text { Funcionarios } \\
\text { en Pasto y } \\
\text { Buenaventura } \\
\text { (Directivos y } \\
\text { operativos) de: } \\
\text { Acción Social, } \\
\text { Defensoría } \\
\text { Regional del } \\
\text { Pueblo, } \\
\text { Secretaria de } \\
\text { Gobierno, } \\
\text { ICBF, } \\
\text { Secretaría de } \\
\text { Salud, } \\
\text { Secretaria de } \\
\text { Educación, } \\
\text { SENA, - } \\
\text { Bancoldex-, } \\
\text { INCODER-, } \\
\text { Banco Agrario, } \\
\text { Dirección de }\end{array}$ & 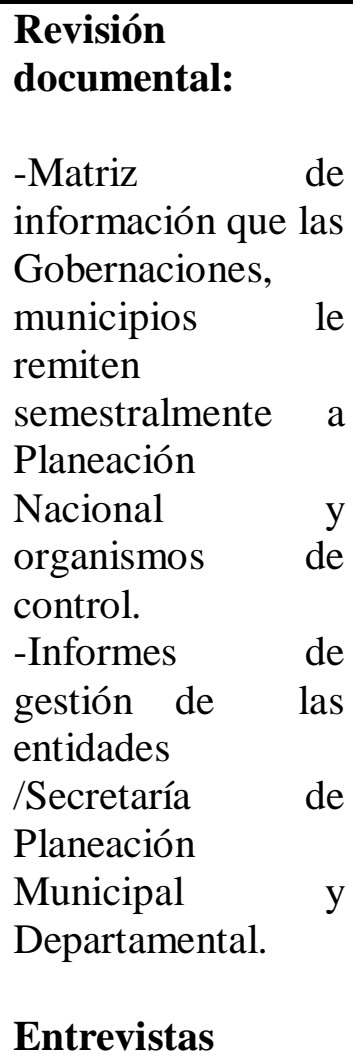 \\
\hline
\end{tabular}




\begin{tabular}{|c|c|c|c|c|}
\hline & & & $\begin{array}{l}\text { Reclutamiento } \\
\text { y } \\
\text { Control } \\
\text { Reserva } \\
\text { del ejercito - } \\
\text { DIRCR, } \\
\text { Universidad de } \\
\text { Nariño (Pasto), } \\
\text {, Fondo } \\
\text { Nacional de } \\
\text { Vivienda, } \\
\text { Instituto } \\
\text { Departamental } \\
\text { de } \\
\text { Salud (Pasto), } \\
\text { Secretaria de } \\
\text { Agricultura y } \\
\text { Medio } \\
\text { Ambiente, } \\
\text { PASTO: } \\
\text { Pastoral social, } \\
\text { Aldea global, } \\
\text { ACNUR, } \\
\text { CICR, Comité } \\
\text { de } \\
\text { Cafeteros, } \\
\text { FUNDEPAZ, } \\
\text { ASOPATIA }\end{array}$ & $\begin{array}{l}\text { semiestructuradas } \\
\text { Cuestionario }\end{array}$ \\
\hline $\begin{array}{l}\text { Identificar } \\
\text { los recursos } \\
\text { asignados } \\
\text { (capacidad } \\
\text { institucional } \\
\text {, recursos } \\
\text { financieros, } \\
\text { talento } \\
\text { humano) } \\
\text { por las } \\
\text { institucione } \\
\text { s para } \\
\text { atender a la } \\
\text { población } \\
\text { en situación } \\
\text { de } \\
\text { desplazamie } \\
\text { nto forzado }\end{array}$ & $\begin{array}{l}\text { Recursos } \\
\text { asignados por } \\
\text { las } \\
\text { instituciones } \\
\text { para atender } \\
\text { a la P.S.D: }\end{array}$ & $\begin{array}{l}\text { - Capacidad institucional: } \\
\text { Estructura física, } \\
\text { acondicionamiento locativo para } \\
\text { garantizar la atención adecuada. } \\
\text { - Recursos financieros: } \\
\text { Esfuerzos presupuestales: avances, } \\
\text { retrocesos, estancamiento y } \\
\text { desafíos de los esfuerzos } \\
\text { presupuestales de las entidades } \\
\text { territoriales en materia de atención } \\
\text { a la población desplazada. } \\
\text { Descripción de los procesos de } \\
\text { atención según priorización de las } \\
\text { instituciones responsables de los } \\
\text { GED. } \\
\text { Conocimiento y aplicación real o }\end{array}$ & $\begin{array}{l}\text { Funcionarios } \\
\text { (Directivos y } \\
\text { operativos) en } \\
\text { Pasto y } \\
\text { Buenaventura } \\
\text { de: } \\
\text { Acción Social, } \\
\text { Defensoría } \\
\text { Regional del } \\
\text { Pueblo, } \\
\text { Secretaria de } \\
\text { Gobierno } \\
\text { Municipal y } \\
\text { Departamental, } \\
\text { ICBF, } \\
\text { Secretaría de } \\
\text { Salud, } \\
\text { Secretaria de }\end{array}$ & $\begin{array}{l}\text { Revisión } \\
\text { Documental } \\
\text {-Plan plurianual de } \\
\text { inversiones } \\
\text { Nacional, } \\
\begin{array}{l}\text { Departamental y } \\
\text { Municipal. }\end{array} \\
\text { Observación } \\
\text { Entrevista } \\
\text { semiestructurada. } \\
\text { Cuestionario }\end{array}$ \\
\hline
\end{tabular}




\begin{tabular}{|c|c|c|c|c|}
\hline $\begin{array}{l}\text { y posibilitar } \\
\text { el goce } \\
\text { efectivo de } \\
\text { sus } \\
\text { derechos. }\end{array}$ & & $\begin{array}{l}\text { no de los instrumentos legales que } \\
\text { tienen y hacen las instituciones } \\
\text { responsables del GED. } \\
\text { - talento humano } \\
\text { No. De funcionarios que atienden a } \\
\text { las P.S.D. } \\
\text { Perfiles y Competencias de los } \\
\text { funcionarios. } \\
\text { Aspectos actutidinales que se } \\
\text { priorizan (ponen en juego) en los } \\
\text { procesos de atención. } \\
\text { Capacitaciones a los funcionarios. }\end{array}$ & $\begin{array}{l}\text { Educación, } \\
\text { Secretaria de } \\
\text { Agricultura y } \\
\text { Medio } \\
\text { Ambiente. } \\
\\
\text { Secretaría de } \\
\text { Hacienda } \\
\text { Municipal y } \\
\text { Dptal } \\
\text { Concejo o } \\
\text { Municipal. }\end{array}$ & \\
\hline $\begin{array}{l}\text { Conocer los } \\
\text { procesos de } \\
\text { gestión y } \\
\text { sinergias } \\
\text { interinstituc } \\
\text { ionales en } \\
\text { los distintos } \\
\text { niveles } \\
\text { territoriales. }\end{array}$ & $\begin{array}{l}\text {-Procesos de } \\
\text { gestión } \\
\text { interinstitucio } \\
\text { nales en los } \\
\text { distintos } \\
\text { niveles } \\
\text { territoriales. } \\
\text {-Sinergias } \\
\text { interinstitucio } \\
\text { nales en los } \\
\text { distintos } \\
\text { niveles } \\
\text { territoriales }\end{array}$ & 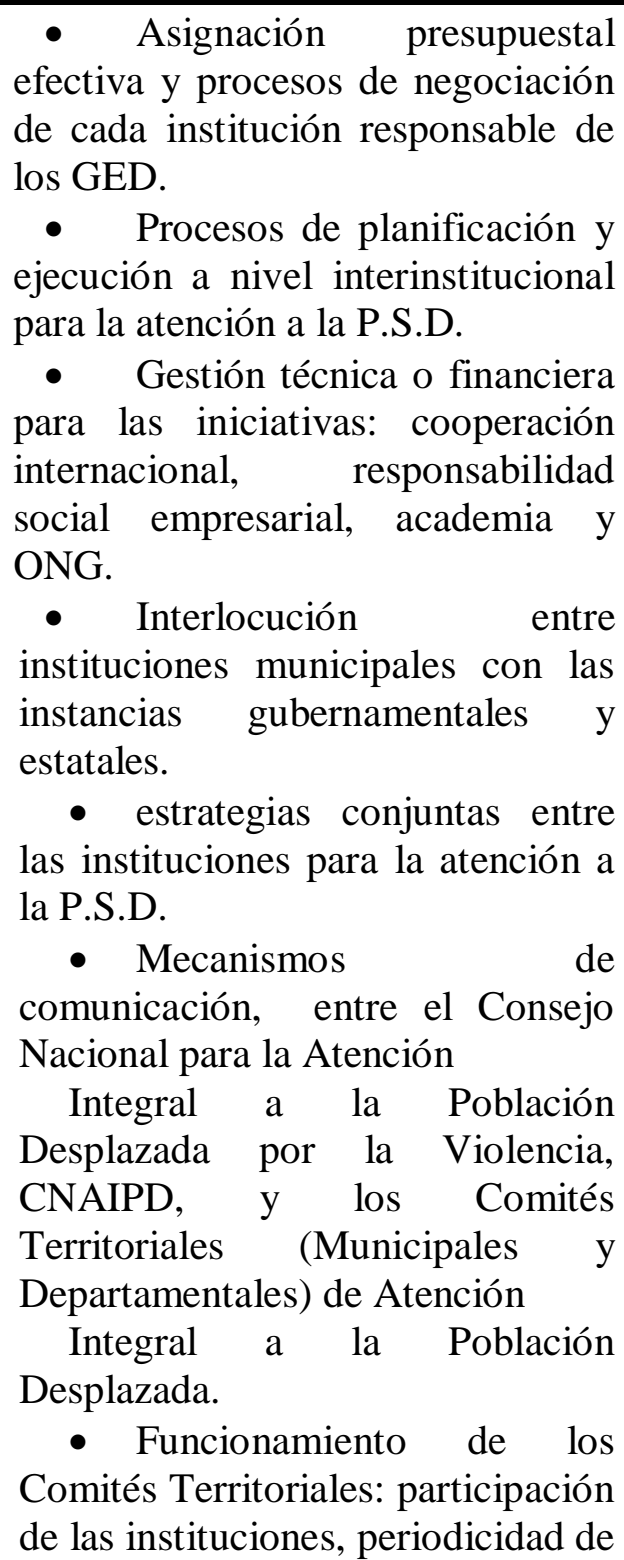 & $\begin{array}{l}\text { Funcionarios } \\
\text { (Directivos) } \\
\text { en Pasto y } \\
\text { Buenaventura } \\
\text { de: } \\
\text { Acción Social, } \\
\text { Defensoría } \\
\text { Regional del } \\
\text { Pueblo, } \\
\text { Secretaria de } \\
\text { Gobierno } \\
\text { Municipal y } \\
\text { Departamental, } \\
\text { ICBF, } \\
\text { Secretaría de } \\
\text { Salud, } \\
\text { Secretaria de } \\
\text { Educación, } \\
\text { Secretaria de } \\
\text { Agricultura y } \\
\text { Medio } \\
\text { Ambiente. } \\
\text { Secretaría } \\
\text { Técnica de los } \\
\text { Comités } \\
\text { territoriales de } \\
\text { Pasto } \\
\text { Buenaventura. }\end{array}$ & 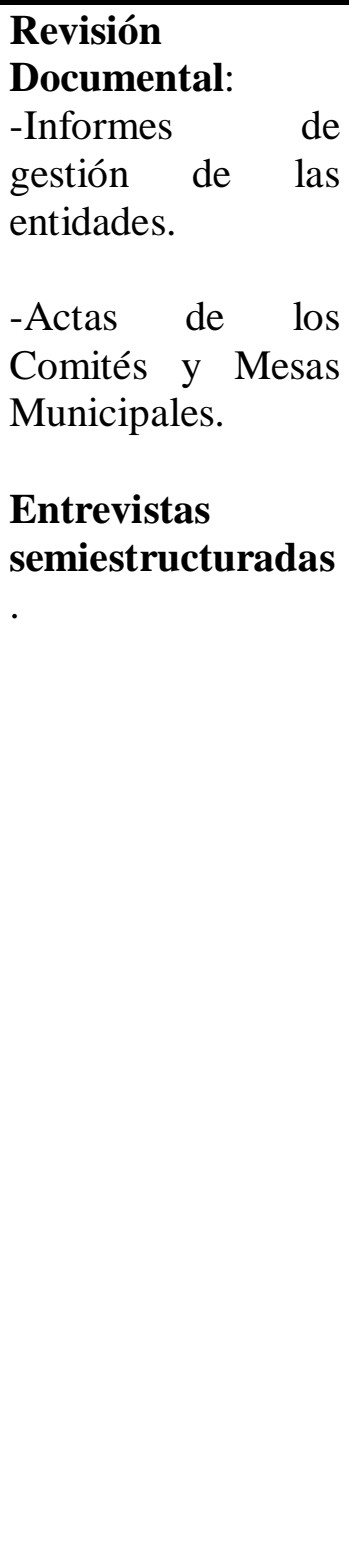 \\
\hline
\end{tabular}




\begin{tabular}{|c|c|c|c|c|}
\hline & & $\begin{array}{lr}\text { encuentros, } & \text { acuerdos } \\
\text { institucionales } & \mathrm{e} \\
\text { interinstitucionales. } & \\
\end{array}$ & & \\
\hline $\begin{array}{l}\text { Analizar la } \\
\text { valoración y } \\
\text { percepción } \\
\text { que las PSD } \\
\text { hacen de las } \\
\text { estrategias } \\
\text { implementa } \\
\text { das por las } \\
\text { institucione } \\
\text { s (estatales } \\
\text { y ejecutoras), } \\
\text { y de sus } \\
\text { propios } \\
\text { repertorios } \\
\text { de acción } \\
\text { para el goce } \\
\text { efectivo de } \\
\text { sus } \\
\text { derechos. }\end{array}$ & $\begin{array}{l}\text {-Valoración } \\
\text { que hacen las } \\
\text { PSD de las } \\
\text { estrategias } \\
\text { implementad } \\
\text { as por las } \\
\text { instituciones } \\
\text { para el GED. } \\
\text {-Percepción } \\
\text { que tienen las } \\
\text { personas de } \\
\text { las estrategias } \\
\text { implementad } \\
\text { as por las } \\
\text { instituciones } \\
\text {-Valoración } \\
\text { que hacen las } \\
\text { P.S.D de sus } \\
\text { propios } \\
\text { repertorios de } \\
\text { acción para el } \\
\text { GED. }\end{array}$ & $\begin{array}{l}\text { - Relevancia, Importancia que } \\
\text { otorgan las P.S.D a las estrategias } \\
\text { institucionales para dar respuesta al } \\
\text { GED. } \\
\text { - Expectativas de las P.S.D } \\
\text { frente a las instituciones de } \\
\text { atención a P.S.D. } \\
\text { - Impresiones, apreciaciones } \\
\text { que tienen las P.S.D. de los } \\
\text { Proyectos, Programas, planes y } \\
\text { acciones que ofrecen las } \\
\text { instituciones. } \\
\text { - Relevancia que otorgan las } \\
\text { P.S.D. a su participación, } \\
\text { utilización de lo medios, } \\
\text { conocimiento y uso de los } \\
\text { mecanismos para exigir sus } \\
\text { derechos. Cons.D. } \\
\text { - Cambios que las P.S.D. } \\
\text { reconocen como agenciados o co- } \\
\text { construidos desde los "contactos" } \\
\text { con las instituciones. }\end{array}$ & $\begin{array}{l}\text { Personas en } \\
\text { situación de } \\
\text { desplazamient } \\
\text { o registradas } \\
\text { en el RUPD. }\end{array}$ & $\begin{array}{l}\text { Entrevistas } \\
\text { semiestructuradas }\end{array}$ \\
\hline
\end{tabular}

La investigación en referencia, fue de tipo DESCRIPTIVO y se llevó a cabo como un "Proceso de Investigación Rápida" que se abordó desde la integración metodológica por combinación de técnicas. El trabajo de campo tomó dos meses y dos meses más para el procesamiento de la información, análisis y elaboración de informe. Fue financiado por la Comisión Nacional de Seguimiento a la Política Pública.

El resultado de la investigación, algunos de los hallazgos, algunas de las preguntas que suscitó y la reflexión sobre los avances o no en el desarrollo de la Política, se sintetizan en el presente artículo. 


\section{Presentación}

"El 22 de enero de 2004, la Corte Constitucional profirió la sentencia de tutela T-025, a través de la cual declaró la existencia de un Estado de Cosas Inconstitucionales (ECI) ante la grave vulneración de derechos de millones de colombianos y colombianas víctimas del desplazamiento forzado y la profunda distancia entre los derechos consignados en la Ley 387 de 1997 y los recursos financieros e institucionales de la política pública destinada a atender esta crisis humanitaria. Esta decisión se produjo como respuesta a la creciente capacidad organizativa de la población desplazada y luego de que miles de personas desplazadas interpusieran recursos de tutela ante la justicia colombiana, para reclamar el acceso efectivo a sus derechos. La sentencia ordena la atención de los derechos básicos de todas las personas desplazadas y establece un proceso de seguimiento en el que participan tanto el gobierno nacional, los organismos de control, las agencias humanitarias de la comunidad internacional, las organizaciones de población desplazada y las organizaciones de derechos humanos" .

Para llevar a cabo el proceso de seguimiento mencionado a partir del año 2005, empezó a funcionar la Comisión de Seguimiento a la Política Pública sobre Desplazamiento Forzado, de la que hacen parte distintas entidades estatales y privadas, en ese marco se ha insistido decididamente en evaluar y hacer seguimiento al cumplimiento de Goce Efectivo de Derechos para la población en situación de desplazamiento. Esta insistencia obedece a la urgencia de superar el estado de cosas inconstitucionales, detectado frente a las personas víctimas del desplazamiento forzado. En el proceso evaluativo el que el grupo "Sujetos Sociales y Acciones Colectivas", participó a través de un "proceso de investigación rápida"’3, en el que se analizaron los casos de Buenaventura y Pasto.

El presente artículo presenta algunos de los hallazgos que seguramente permitirán identificar los avances, retrocesos y permanencias sobre este "estado de cosas inconstitucionales", en los dos Municipios estudiados.

\footnotetext{
${ }^{1}$.http://www.codhes.org/index.php?option=com_content\&task=view\&id=39\&Itemid=52: Comisión de seguimiento a la política pública sobre desplazamiento forzado. Consulta: Mayo 272009.

${ }^{2}$ De la Escuela de Trabajo Social y Desarrollo Humano Universidad del Valle.

${ }^{3}$ Llevado a cabo entre agosto 2008 a enero 2009, a través de la metodología de integración metodológica (Cuali cuanti), con las entidades, instituciones del sistema de atención a las PSD y con las personas víctimas del desplazamiento forzado en las dos ciudades.
} 


\section{A propósito de la Atención a las Personas en Situación de Desplazamiento (PSD):}

El SINAPD (Sistema de atención a las Personas en Situación de Desplazamiento), se supone como un "mecanismo" en el que confluyen entidades estatales de nivel nacional, territorial, regional y local a fin de propiciar una atención adecuada a la problemática del desplazamiento forzado, un proceso de restitución de los derechos vulnerados y una serie de garantías para que efectivamente sea viable este propósito. De este sistema se derivan desarrollos interesantes en torno al tema, por ejemplo el PIU ${ }^{4}$ (Plan Integral Único) como

“...una herramienta muy importante de planeación estratégica que se realiza de manera colectiva y participativa y que se construye en el marco de los Comités Territoriales de Atención Integral a la Población Desplazada-CTAIPD constituyéndose en un mecanismo de coordinación de acciones de prevención y atención al desplazamiento forzado por la violencia, entre las diferentes instituciones del nivel nacional, departamental y municipal que hacen parte del Sistema Nacional de Atención Integral... ",

De otra parte, la atención a las PSD supone las siguientes fases las cuales señalan que en términos de la política y la perspectiva estratégica, hay una intencionalidad clara, cual es la de garantizar el goce efectivo de derechos para las PSD:

\section{Prevención y Protección}

2. Fase de Atención de humanitaria emergencia

3. Fase de Estabilización socio - económica

No es ni mucho menos optimista la mirada frente a los desarrollos de estas fases, no solo en las ciudades de Buenaventura y Pasto, sino en varias localidades analizadas a nivel nacional por la Comisión y.

\footnotetext{
${ }^{4}$ El Plan Nacional aprobado mediante el Decreto 250 de 2005 modifica el anterior plan expedido por el Decreto 173 de 1998.

${ }^{5}$ Acción Social - Presidencia de la República de Colombia. Boletín Informativo 2008.
} 


\section{Caso Pasto:}

\section{Fase de Atención Humanitaria:}

La UAO (unidad de atención y orientación Municipal para la atención a la población en situación de desplazamiento), define metas e indicadores que le permiten medir acciones en esta fase; sin embargo, existen muchas dificultades en esta fase que no permiten el acceso al Goce Efectivo de Derechos de la Población en Situación de Desplazamiento, por ejemplo, una de las metas que se propone:

Se brindará atención humanitaria por emergencia y se garantizará los servicios básicos de educación, salud y complementarios a la población en situación de desplazamiento forzado por conflicto violento.

El cumplimiento de esta meta, depende del acceso a la oferta institucional de las personas en situación de desplazamiento, deben en primer lugar realizar la declaración ante el Ministerio Público o Acción Social; tras un proceso de espera en un periodo de no menos quince (15) días para la obtención de respuesta de inclusión o no en el sistema. Entre las dificultades están el horario de atención que se ajusta a una lógica institucional: de 7am a $12 \mathrm{~m}$ y de 2 a $5 \mathrm{pm}$, muchas veces las personas no logran presentarse en este horario, lo que impide que puedan recibir respuesta frente a las demandas que expresan:

"[...] ahí fuimos en la mañana no alcanzamos turno porque atienden cierto número entonces toca que estar bien [...] antes de las 7 o antes de la 2 para alcanzar y dar la declaración"

[Lideresa PSD]

Así mismo, algunos líderes y lideresas afirmaron que el proceso de declaración no es nada fácil y que por el contrario a veces se presentan en esta fase de la atención algunas trabas u obstáculos que impiden que puedan realizar esta acción, lo cual es un obstáculo contundente para dar continuidad al proceso

"[...] la asistencia humanitaria es complicado lograrla por las trabas que se le ponen para tomar una declaración y las ayudas, ..." 


\section{[Lideresa PSD]}

Para el caso de Pasto, en esta fase (de Atención Humanitaria) participan: Acción social, el Instituto Colombiano de Bienestar Familiar, el Consejo Noruego (Cooperación Internacional), Atención en salud y Pastoral Social. Enfatizan en la atención de urgencia, que se dirige a satisfacer las necesidades básicas de alimentación, salud y alojamiento de las personas que acaban de desplazarse. Las Personas Víctimas del Desplazamiento que han rendido declaración, reciben asistencia psicosocial y se les ofrece albergue y alimentación por medio de la casa de paso.

“...es un programa que tenemos nosotros, que es un albergue, que es la casa de paso. Es la única casa de paso que existe en Pasto y que está diseñada exclusivamente para población desplazada; tiene casi cinco años de creada y se creó exclusivamente para eso, porque las personas no tenían un sitio, porque llegan temporalmente a la ciudad mientras declaran ante el Ministerio Público... duran quince días mientras el Ministerio Público les da respuesta.... ...Albergue, alimentación, atención psicosocial, otro se le hace el seguimiento a los casos, es un programa bien interesante y muchas organizaciones sociales lo ayudan"

[Funcionario Pastoral Social]

Así mismo, a estas personas se les ha dado dinero en efectivo para que puedan pagar un arriendo durante los tres primeros meses que les cubre la ayuda humanitaria, tal como lo exige la ley.

En cuanto a los servicios de salud en esta fase de atención, en las entrevistas y conversaciones con la $\mathrm{PSD}^{6}$ se encontró que a las familias que acaban de realizar la declaración y no han sido notificados de su inclusión en el sistema, no se les está brindado la atención, por lo cual Profamilia asume la atención de estas personas. Lo grave del asunto es la complejidad del proceso de la declaración y confirmación de la inclusión en el sistema, es una ruta por demás re-victimizante y que vulnera sustancialmente los Derechos de las Víctimas.

\footnotetext{
${ }^{6}$ Personas en Situación de Desplazamiento.
} 
Lo anterior dejar ver que pese al despliegue de recursos y movilización institucional para la Atención Humanitaria hay falencias graves en el proceso.

"Yo les hablo a ellos que hay que hacer valer sus derechos, que ellos no vienen a pedir caridad, que uno de los derechos fundamentales que ellos tienen es rendir una declaración y que les den respuesta a esa declaración. Otro derecho es el derecho a salud, a la educación, pero que exijan esos derechos".

[Funcionaria UAO]

\section{Fase de Estabilización:}

Al mismo tenor de la fase presentada anteriormente, la UAO se plantea como meta:

Se cofinanciara el $15 \%$ de los proyectos identificados por el PIUR (Programa Integral Único de Restablecimiento) para el restablecimiento de la población en situación de desplazamiento.

La estabilización socioeconómica refiere al goce efectivo en derechos como educación, salud, generación de ingresos, entre otros, y tiene en cuenta aspectos de la atención como la aplicación del enfoque diferencial ${ }^{7}$. Si tomamos el caso de la Atención en Educación, cabe destacar en cuanto a la atención a Niños, Niñas y Adolescentes en situación de desplazamiento forzado (NNAD), sobresale el acceso a cupos para educación básica primaria y secundaria y algunos cupos especiales para educación superior en la Universidad de Nariño. También se vinculan los NNAD a los programas de ICBF como, Hogares comunitarios de Bienestar (Hogar fami y Hogar 0-7 años), Programa Restaurante Escolar, Recuperación Nutricional, Desayunos Infantiles, Centros de Atención Múltiple y Hogar Infantil.

En esta fase es importante destacar algunos aspectos desde los funcionarios de las mismas entidades:

"La gente que llega a buscar trabajo, sobre todo las mujeres... a ellas las discriminan muchísimo, o sea las ponen a lavar montones

\footnotetext{
${ }^{7}$ De Género, Étnico y Generacional (o Etáreo).
} 
de ropa, y a cocinar y no les pagan bien. Ejemplo: un caso de una señora estaba en un restaurante, le tocó trabajar desde las cinco de la mañana hasta las once de la noche y no le pagaban porque le daban el almuerzo, a ella, al compañero y al niño. Entonces son situaciones bien difíciles, la gente se aprovecha mucho de ellos, por eso es tan tremendo verlos aquí, por las ayudas. Y estas se demoran, además con niños, y verlos muriendo de hambre...".

[Funcionaria UAO]

Se reconocen algunos avances en esta materia (nivelación, círculos de aprendizaje, apertura de cupos), incluso la ampliación de cobertura. No obstante, los funcionarios identifican que las familias no logran cubrir los gastos de útiles escolares, uniformes y otros, lo que se constituye en una causal de deserción escolar. Esta dificultad de acceso sigue demostrando las condiciones de pobreza e insatisfacción de necesidades de la población en situación de desplazamiento forzado. Adicionalmente hay que plantear que el nivel de adhesión al sistema escolar por parte de los niños, niñas y jóvenes depende en gran parte de la interacción pedagógica con sus profesores y profesoras, quienes NO están “equipados” con herramientas y en ocasiones no están sensibilizados frente a las personas víctimas del desplazamiento forzado, lo cual genera dificultades profundas y pone en riesgo la permanencia con calidad del niño, niña o joven en la escuela.

Se reconoce finalmente, la participación y alianzas interinstitucionales: SENA, Secretaría de educación, UAO, algunos colegios públicos, y la Universidad de Nariño (UDENAR), en el proceso de restitución del derecho a la educación, lo cual, según los funcionarios entrevistados no solo ha permitido un amplio y rápido acceso o reingreso de los niños, las niñas y los jóvenes al sistema educativo, sino que también ha posibilitado la vinculación de adultos iletrados a programas de nivelación educativa $\mathrm{y}$, sobretodo, a programas de formación ocupacional y para el trabajo. No obstante, el acceso de la PSD a la educación superior, no es fácil.

Con relación a la atención psicosocial poco es el avance o si se dice aplicar no existen unas estrategias que permitan implementar este tipo de atención, en asuntos específicos como es la elaboración del duelo, la recuperación de la memoria que trasciende el hecho de 
centrarse exclusivamente en el episodio traumático, sino que más bien busca transitar por la temporalidad pasado, presente y futuro que permita que las PSD se ubiquen y transiten desde su doble condición: como víctimas y como sujetos de derechos.

En cuanto a generación de ingresos, principalmente tienen que ver con capacitaciones técnicas puntuales, encaminadas hacia la productividad, elaborados desde un enfoque empresarial, que busca incentivar en las PSD su "espíritu emprendedor"; que estas personas logren diseñar su propia estrategia de venta y generar recursos a partir de la misma, para el sostenimiento familiar, procesos que en muchos momentos desconoce la historia de la población y sus lugares de procedencia.

Las estrategias implementadas en esta área se sintetizan en tres aspectos: 1) Formación y capacitación para acceder al mercado laboral en la ciudad, de acuerdo a las demandas del mercado; 2) asesoría y capacitación para la creación de unidades productivas y entrega de capital semilla, 3) Educación formal, enmarcado en varios programas de aprendizaje para adultos.

Estas estrategias implementadas, de acuerdo a la población beneficiaria, no tienen un proceso de seguimiento ni se han abordado de acuerdo a las características, necesidades, saberes y expectativas de las familias; en esta medida, las unidades productivas no son y no brindan un panorama claro frente a un proyecto productivo y su sostenibilidad.

Para cerrar el caso del Municipio de Pasto, vale la pena mencionar algunas concepciones que los funcionarios de las instituciones del SINAPD, tienen sobre el GED:

"Ahí es otro problema serio, ahi hay una situación de déficit de ese goce de derechos previo al desplazamiento, porque la mayor parte de la población ya antes del desplazamiento tiene un déficit de derechos, un déficit del goce de derechos -¿no?- desde el lugar donde están, y eso viene y se agrava con todo este drama que trae implícito el desplazamiento. Entonces yo diría que se potencia aún más ese déficit, pues cuando se presenta ya el desplazamiento; y en tercera instancia cuando uno no ve una respuesta estatal adecuada para tratar, paliar un poco esa situación” 
"El goce efectivo, eh... yo a veces he tenido la impresión de que muchas veces a la población desplazada, sobre todo en zonas rurales, en zonas rurales aqui en Nariño... el goce efectivo de sus derechos pasa más por una estrategia existencial de considerar bueno lo enmarcadito o lo puntual y no como una población que realmente ha tenido el derecho a poder vivir donde quiere, el derecho a poder trabajar donde quiere, el derecho a poder enviar sus hijos al colegio, el derecho a poder desplazarse libremente, el derecho a poder decidir donde se queda o donde se va..."

[Funcionario ACNUR Nariño y Putumayo-2008]

\section{Caso Buenaventura:}

"En la medida que a ellos se les da todo lo necesario, que salgan de su condición, se puede decir que se les da el goce efectivo, ¿no? Entonces, acabamos de realizar una jornada de atención masiva a población desplazado con el objetivo de que ellos....de mirar hasta dónde se ha cumplido, qué está pendiente con ellos, para darle respuesta a esta problemática. Pero como te digo en cuanto a habitabilidad, usted sabe que esos proyectos son a largo plazo. O sea, no son inmediatos. Entonces, en la medida que se puede, se les va dando salida. Pero la población aquí es bastante grande. Poco a poco hemos ido ampliando cobertura para cada uno de los programas que tienen que ver con salud, educación, vivienda."

[Funcionaria Red Juntos]

Para presentar desde una perspectiva distinta a la del caso Pasto, partamos por reconocer que la ruta de atención tiene problemas en el registro de la población desplazada, limitantes en la realización de visitas domiciliarias ${ }^{8}$ de diagnóstico y seguimiento, demoras en el suministro de información que retrasa los procesos de inclusión, incapacidad para crear estrategias para atender de manera agil y amable a las personas en la UAO, dificultades para inclusión de procesos formativos de la PSDF y en menor medida encontramos reflexiones en torno a las acciones implementadas por las instituciones para hacer frente a dichas dificultades.

\footnotetext{
8 Razones: influencia de grupos armados en la zona urbana, situación que pone en riesgo el ingreso de funcionarios a estas zonas; la ciudad no cuenta con un sistema de nomenclaturas que permita ubicar las viviendas de las personas; la Continua movilización de familias que se desplazan de un barrio a otro dadas las condiciones de conflicto intra-urbano presentes en la ciudad.
} 
Algunos funcionarios mencionaron problemas de subregistro por dos razones: por un lado, la base de datos no es consistente. Hay también problemas de retraso en el suministro de las declaraciones tomadas por la procuraduría las cuales deben ser entregadas a la Acción Social para ser enviadas a la ciudad de Bogotá donde es realizado el análisis que determina si el núcleo familiar es o no incluido en el registro. Dicho retraso dificulta el proceso de inclusión de los declarantes en el SIPOD.

Otra dificultad identificada está mediada por la falta de documentos de identidad, situación que limita los procesos de atención, en tanto, el documento de identidad es importante como fuente de verificación ante todo tipo de trámite que la persona realice, asunto que es viable pero en las circunstancias en las que habitualmente las personas son desplazadas, que implica salir de un momento a otro y en el mejor de los casos con lo "mínimo" que pueden sacar y cargar.

En este panorama y como lo han reiterado otros estudios, la Acción de Tutela se ha convertido en un procedimiento para el acceso a los derechos vulnerados. La población instaura constantemente este tipo de mecanismos para acceder a las fases de atención, lo cual se ha convertido casi en un requisito antes de obtener respuestas, de nuevo, sometiendo a situaciones de doble victimización a las PSDF.

Uno de los aspectos que identifican como dificultad para el acceso a las estrategias de atención, son las inadecuadas instalaciones física de las instituciones de la UAO en la ciudad de Buenaventura, ante esta situación, funcionarios de instituciones de orden no gubernamental consideran que teniendo en cuenta las limitaciones físicas que se tienen, la atención debería ser permanente, contemplar mayor cantidad de horas, por la cantidad de personas que llegan a las instalaciones de la UAO para solicitar atención, hacen largas filas. Situación que pareciese no tener eco en acciones de los entes gubernamentales para revertir dichos problemas.

En contraste, se destaca en la información brindada por los y las funcionarias en relación a las formas como acceden a la oferta las personas víctimas del desplazamiento: UAO, Acción Social, Profamilia, SENA, Fundación Caritas y la Umata, realizan convocatorias públicas sobre sus programas y proyectos. En el caso de la Fundación Caritas, por ejemplo, 
se realizaron alianzas estratégicas con otras instituciones que informen sobre los servicios que ofrece la institución y remitan a la PSDF, igual ocurre con Profamilia, estas instituciones trabajan en articulación con la UAO, para identificar, registrar, apoyar y orientar a PSD. La entidad se desplaza hasta la comunidad si es necesario a través de unidades especiales, mediante las cuales atienden a PSD (brindando servicios inmediata en salud y orientación psicosocial) y difunden información, como lo muestran los siguientes fragmentos de entrevistas:

"Ellos cuando se inscriben en la UAO, ellos dejan sus datos, celulares, direcciones. Lo que hacemos es eso. Es llamar o visitar -si no hay teléfono pues...- la casa que ellos nos dejaron o a través de los consejos comunitarios. Entonces los líderes de los diferentes barrios, de zona, nos dicen, pasamos el registro de cédulas o nos convocan un grupo de población que esté en situación de desplazamiento. Nosotros llegamos y buscamos a las personas que tenemos para vincularlas en el proyecto. En otros casos pues la gente...los mismos vecinos, pues comentan y ellos vienen aquí. Pero digamos que la Fundación CARITAS en el año que lleva aquí pues la gente ya como que...a veces llegan aquí pues pensando que es una oficina de Acción Social. Entonces a veces llegan mucho aquí, que se van a registrar entonces [les] decimos "no, esto es una fundación, CARITAS que trabaja para esa población pero no hacemos ese procedimiento". Pero la Fundación se ha dado a conocer. Por lo menos en la población la gente conoce y sabe que estamos trabajando en el Programa de Generación de Ingresos. Nunca nos hemos dado cuenta por radio, televisión"

[Coordinador psicosocial Fundación Caritas].

"A través, de... del trabajo con las diferentes entidades, si me entiendes, o sea, por lo menos, hay entidades que saben, por lo menos la Secretaria de Convivencia trabaja específicamente en la Alcaldía con eso, entonces nosotros le damos a conocer a ellos, la UAO también se le da el conocimiento de que nosotros estamos trabajando esta parte acá, y en todos los actores que pertenecen al sistema nacional de Bienestar Familiar, además ICBF también pertenece al equipo que se creó de la Red Juntos, es que existe aquí en Buenaventura el comité para la población desplazada y Bienestar es uno de los miembro de ese comité" [ICBF]

Estas instituciones trabajan fuertes componentes de atención psicosocial inmediata y a mediano plazo, familiar e individual (De acuerdo a la cobertura que manejen cada 
institución), acompañamiento en comunidad, asistencia humanitaria de emergencia según el caso.

El traslado de parte del personal de las instituciones, en representación de las mismas hasta las comunidades donde se tiene conocimiento de la existencia de PSD, y la difusión en dichos sitios de la información sobre los servicios de las instituciones en apoyo con líderes de las PSD (Madres comunitarias, voceros), es una de las estrategias que más se menciona en las entrevistas por los funcionarios. Se resalta que una de las formas de dar información a la PSD ocurre cuando la PSD acude a las instalaciones de las Instituciones estás presentan variaciones en su forma de atención, dependiendo si son entidades generadoras de programas y recursos u operadoras de proyectos.

Esta suerte de itinerancia se entiende también por el problema de desplazamiento intraurbano, identificado en Buenaventura como una constante que apenas se empieza a visibilizar:

\section{El Desplazamiento Intraurbano: una situación conexa al DF}

Actualmente es un escenario con una aguda situación de violencia, inseguridad y crisis humanitaria, donde el desplazamiento forzado se constituye en una problemática social grave por las dimensiones del fenómeno: en primer lugar, el Municipio reporta cifras altas como receptor y a la vez expulsor, en segundo lugar, el desplazamiento forzado en el Municipio tiene una dinámica particular, marcada por las formas de resistencia de las comunidades y el desplazamiento intraurbano ${ }^{9}$.

Con relación a las comunidades en resistencia tienen como estrategia que los pobladores de la zona rural del Municipio afectados por el conflicto armado, social y político del país, no salgan de los territorios sino que se desplacen a lo largo de los ríos en forma "nómada" y de esta manera, puedan regresar al territorio de donde salieron. Esta estrategia viene siendo

\footnotetext{
${ }_{9}^{9}$ Procesos de Desplazamiento en la misma ciudad, de un barrio a otro, de una comuna a otra. Especialmente marcado por la simbólica división territorial de la ciudad entre milicias de los distintos grupos y las mismas fuerzas del Estado; entre distintos grupos conexos con las dinámicas subterfugias del narcotráfico y el contrabando; y las pandillas urbanas que con frecuencia tienen conexiones con unos y otros.
} 
implementada, especialmente, por los Consejos Comunitarios de Comunidades Negras, constituidos en el marco de la ley 70 de 1993; actualmente en el municipio según datos que muestra el documento defensorial ${ }^{10}$, diciembre de 2007, existen 42 consejos comunitarios de comunidades negras, 8 de cuencas y 34 veredales.

"buscamos la única metodología es no salirse del territorio, esa es la única función, porque como dijo el compañero el Gobierno a través del paramilitar y del ejército quieren invadir el territorio de nosotros por la riqueza que hay, entonces nosotros sabemos que si salimos del territorio, es un territorio que si está vació, es espacio que el enemigo permanece allí, estamos tratando de estar siempre en el territorio para hacerle resistencia a toda esa opresión, por eso no nos salimos de allá hacemos los desplazamientos internos del río, de allá no nos venimos porque entonces estamos dejando sólo el territorio y cuando regresemos entonces vamos a encontrar todo anormal, gente que no es de allá, paisas, de todas estas cosas"

[Líder 1 en situación de desplazamiento]

Llama la atención este tipo de resistencia, por un lado, porque ubica claramente el actor de confrontación, en este caso, la alianza Estado y fuerzas paramilitares, según lo refiere el entrevistado, y por otra parte, el análisis que se hace de las causas del desplazamiento forzado como "estrategia de desarrollo", con acciones puntuales y continuas, en contextos urbanos.

En este mismo sentido y según el informe de la misión de acompañamiento humanitario a comunidades urbanas del Distrito Especial de Buenaventura, el desplazamiento intraurbano:

"resulta atípico debido que la población se desplaza temporalmente hacia otros barrios, buscando protección en casas de familiares y conocidos, y en ocasiones regresan a sus viviendas en horas del día con la finalidad de evitar el saqueo y la ocupación de los actores armados legales e ilegales. Estas características del desplazamiento intraurbano dificultan la atención humanitaria de emergencia de las instituciones responsables de la misma",11

\footnotetext{
${ }^{10}$ Defensoria del Pueblo (2008). Informe Misión de acompañamiento humanitario a comunidades urbanas del Distrito Especial de Buenaventura. Defensoría Regional del Pueblo - Valle del Cauca. Buenaventura.

${ }^{11}$ Bello, Marta Nubia (2004). BELLO, Martha Nubia (2004): El desplazamiento forzado en Colombia: acumulación de capital y exclusión. En: Desplazamiento forzado: Dinámicas de guerra, exclusión y desarraigo, ACNUR, Universidad Nacional de Colombia, Bogotá.
} 
Abello refiere la dificultad que genera el desplazamiento intraurbano para la atención humanitaria, aunque también debe reconocerse que este genera problemáticas conexas como la separación de familias, la pérdida de tejidos vecinales, las pèrdidas de vivienda y proyectos productivos relacionados con los contextos barriales.

Con estos apuntes más bien fragmentados, puede observarse que los casos de Buenaventura y Pasto, en el tema de Goce Efectivo de Derechos no muestran avance en la atención, contención de la problemática y/o progreso para superar esta que debiera ser una condición transitoria. Por el contrario, nos muestra la paulatina complejización de la situación misma y la enorme distancia que hay entre la superación de cosas inconstitucionales y la realidad.

\section{$\underline{5}$ Algunas Conclusiones:}

- Tanto en Pasto como en Buenaventura, los Desarrollos Institucionales para GED de las Personas en Situación de Desplazamiento son incipientes, pasan en primera instancia por obstáculos de conocimiento frente a los mismos, pasa por interpretaciones diversas y en algunos casos "reduccionistas". Pasa por dificultades estructurales como la burocracia institucional, la poca o nula coordinación interinstitucional, la baja o nula asignación presupuestal desde los distintos niveles territoriales (local - regional - nacional). Y pasa también por condicionantes como la voluntad política, las negociaciones clientelistas, y los ritmos políticos de la dinámica democrática.

- $\quad$ Si bien es cierto que en Buenaventura y Pasto hay lo que puede llamarse una "legislación local" relacionada con la Política Pública de Atención a Personas en Situación de Desplazamiento, no es menos cierto que la efectividad de las mismas se complica también por los procesos de descentralización, que en parte complejizan el acceso a los recursos financieros y los procesos de toma de decisiones. En ese mismo sentido puede considerarse que hay una "ruta" ideal trazada, pero su aplicabilidad real tiene elementos contingentes. 
- Unas veces por desconocimiento, otras porque no se tienen en cuenta, otras porque el presupuesto no lo permite, no hay una aplicabilidad efectiva del enfoque diferencial por grupo etáreo, étnico, género y discapacidad. Aunque debe reconocerse algunos intentos específicos en Pasto a través de proyectos con perspectiva de género, con el tema de alimentación, o porque las instalaciones de la UAO cuenta con ramplas para las y los discapacitados; pero no hay una estrategia transversal que procesualmente aplique el enfoque.

- se logra evidenciar que las personas en situación de desplazamiento que se encuentran en las ciudades de Pasto y Buenaventura, no logran el goce efectivo de sus derechos, en esta medida no han logrado una estabilización socioeconómica (se identifica falta de oportunidades, desempleo, o trabajo informal), ni el acceso integral a derechos como la salud, la educación y vivienda. Esto probablemente a las rutas criticas de atención identificadas que están directamente relacionadas con la poca capacidad institucional para dar respuesta a la problemática. En esta medida, se evidencian deficiencias en la estructura física, en tanto no existe un espacio apropiado para atender al número de PSD, la demanda de atención desborda la capacidad de la oferta institucional, además no se cuenta con espacios diferenciados y privados para la orientación, los cuales son fundamentales, especialmente para la atención psicosocial, punto de partida clave para lograr GED.

- Un hallazgo importante que cabe para Pasto y Buenaventura, es que se privilegia la atención humanitaria y de emergencia y en la fase de estabilización socio - económica. No hay mayores desarrollos en las fases de Prevención y Protección. Dos problemas identificamos con relación a ello: el primero es que el no desarrollo de la Prevención y Protección señala que el Desplazamiento seguirá creciendo de manera exponencial; y un segundo problema es la perspectiva de la Estabilización Socioeconómica centradas en la capacitación en torno a proyectos productivos y un capital inicial para "montar su propio negocio", obviando muchas veces la propia historia, las vocaciones, y las potencialidades propias de las PSD; además de señalar de manera indirecta una renuncia a la posibilidad de retorno. 
- Cabe señalar desde el sentido, práctico que el proceso de declaración como lo han concebido en los Municipios obvia las consideraciones mínimas del trato humano y dada la compleja ruta que se sigue, incluso se re - victimiza a las PSD, quienes deben someterse a cada paso del proceso independientemente del tiempo que implique y deben reconstruir su relato a cada funcionario que lo exija, convirtiendo incluso este evento de ruptura vital en un requisito funcional para poder hacer la declaración.

\section{BIBLIOGRAFIA}

ALCALDÍA MUNICIPAL DE BUENAVENTURA, Oficina de Convivencia para la Sociedad Civil - Coordinación Municipal de Juventud (2007). Informe de gestión año 2007. Documento Power Point (versión digital).

ALCALDÍA MUNICIPAL DE PASTO. Plan de Desarrollo municipal de Pasto. 2008 2011 "Queremos más - Podemos más"

ALMARIO, Oscar (2007). “ ¡Ay mi bello puerto del mar, mi Buenaventura! La larga historia del desencuentro entre el puerto y la ciudad y entre la región y el país”. En: Revista Posiciones. $N^{\mathrm{o}}$ 1. Universidad del Valle. Cali.

ACNUR (2007). Balance de la política pública de para la atención integral al desplazamiento forzado en Colombia Enero 2004 - abril 2007. UNHCR/ACNUR, Bogotá.

BELLO, Martha Nubia (2004): El desplazamiento forzado en Colombia: acumulación de capital y exclusión. En: Desplazamiento forzado: Dinámicas de guerra, exclusión y desarraigo, ACNUR, Universidad Nacional de Colombia, Bogotá.

CERÓN, Benhur (2008). "Violencia y desplazamiento forzado, implicaciones en el departamento de Nariño y Pasto". En: Manual de Historia de Pasto. Tomo IX. Academia Nariñense de Historia.

RODRÍGUEZ Alba Nubia y GÓMEZ Sheila: (2007). Organizaciones sociales de Personas en Situación de Desplazamiento; identidad y ciudad. En: Restablecimiento, reparación y procesos organizativos de la Población en Situación de desplazamiento. Reflexiones y avances investigativos. Mario Hernán López... [et. al]. -Editado por: Diana Patricia Ortiz, Mario Hernán López y Mauricio Viloria. Fundación Universitaria del Área Andina. Pereira.

CODHES Y CONFERENCIA EPISCOPAL DE COLOMBIA. (2006) Desafíos para 
construir nación. El país ante el desplazamiento, el conflicto armado y la crisis humanitaria. 1995-2005. Bogotá,

(2008). Desplazamiento Forzado y Enfoques Diferenciales. Documentos 9. Bogotá - Colombia.

Defensoría del Pueblo (2008). Informe Misión de acompañamiento humanitario a comunidades urbanas del Distrito Especial de Buenaventura. Defensoría Regional del Pueblo - Valle del Cauca. Buenaventura. 